\title{
Demografía, desarrollo y control del espacio litoral en la costa del Pacífico mexicano
}

\author{
Demography, Development and Control of the Coastal Space on \\ the Pacific Coast of Mexico
}

GRACIELA ALCALÁ

Instituto Politécnico Nacional, México

RESUMEN Durante las últimas cuatro décadas del siglo pasado el crecimiento demográfico de México ha ido disminuyendo ostensiblemente. Esta tendencia ha continuado incluso durante la primera década del siglo XxI, a tono con las expectativas vigentes sobre el tema en el país. Sin embargo, y precisamente durante las mismas décadas, en los territorios costeros del país se viene presentando un fenómeno inverso, es decir, un crecimiento demográfico resultante de la migración hacia ellas, no del crecimiento promedio de las tasas de natalidad que, por cierto, se mantienen más o menos semejantes a las que imperan entre el resto de habitantes de la nación. Este fenómeno por sí mismo es prueba fehaciente del crecimiento de la inversión de capital tanto pública como privada en los territorios costeros. La única excepción a esta tendencia es la de tres municipios costeros sinaloenses creados a principios de la década de 1990 y tomados literalmente por las actividades del narcotráfico. Los nuevos habitantes de las costas mexicanas suelen ser en su inmensa mayoría personas llegadas de tierra adentro en busca de trabajo que les permita alcanzar mejores condiciones de vida. Para estos "costeños» de nuevo cuño la vida en esas latitudes es completamente distinta a la que llevaban en sus lugares de habitación anterior hayan sido éstos el altiplano o la mesa central, los desiertos norteños, los calcáreos terrenos del interior de 
la península de Yucatán o las intrincadas laderas de nuestras montañas: nuevos el ritmo y la manera de trabajar, distintas las costumbres alimenticias y de vestimenta locales, desconocidos los fenómenos climáticos y sus consecuencias en la vida cotidiana, extraños los modismos idiomáticos, exótico, en fin, el aprecio de los nativos costeños por su paisaje y su flora y fauna locales. Para analizar el caso de estudio se propone el concepto de «región costera", haciéndose uso de información demográfica a nivel nacional y en los Estados y municipios costeros que provienen de los censos nacionales de población y vivienda de las décadas de 1950 a 20 Io publicados por el Instituto Nacional de Estadísticas, Geografía e Informática (INEGI), además de imágenes fotográficas que provienen de diversos archivos y de los de la propia autora. El «diseño experimental» no es posible para el tema que abordo pues no se trata de «experimentar» sino de intentar explicar lo que sucede entre los habitantes de las costas mexicanas a partir de su situación a lo largo de alrededor de 50 años de historia de colonización constante.

PALAbras CLAVe Región costera, desarrollo costero, costas de México.

RESUMEN During the four final decades of the last century, demographic growth in Mexico slowed significantly. This trend continued during the first decade of the 2 Ist century, in tune with current expectations in the country. However, during precisely the same decades, the opposite phenomenon has been occurring in the country's coastal territories, i.e. demographic growth resulting not from an increase in average birth rates, which have followed more or less the same trends as among the rest of the country's inhabitants, but from immigration into these areas. This phenomenon is of itself reliable proof of the growth in investment of both public and private capital in coastal territories. The only exception to this trend is provided by three coastal municipalities in the state of Sinaloa, created in the early I990s and taken over, literally, by drug-trafficking activities. The vast majority of these new inhabitants of the Mexican coastlines are people who have arrived from inland in search of jobs, in the hope of improving their lives. For the new "costeños», life in these latitudes is completely different to that which they had experienced in their previous homes, whether in the plateau or the central plain, the deserts of the north, the limestone country of the interior of the Yucatán peninsula or the tortuous hillsides of the mountains: new rhythms and ways of working, different local eating habits and modes of dress, unknown climatic phenomena and their consequences for daily life, strange idiomatic expressions, and finally the exotic affection of the 
native "costeños» for their countryside and their local flora and fauna. To analyse the case study, we propose the concept of the «coastal region». We use demographic information both at national level and from the coastal states and municipalities, taken from national censuses of population and housing done in the decades from 1950 to 2010 , published by the Instituto Nacional de Estadísticas, Geografía e Informática (National Institute of Statistics, Geography and IT, INEGI), as well as photographs from various archives and from the author's collection. It is not appropriate to talk of an «experimental design» in this work, since it is not an «experiment» but an attempt to explain what has been happening among the inhabitants of the Mexican coasts on the basis of the developing situation over some 50 years of constant colonisation.

KEYWORDS Coastal region, coastal development, Mexican coasts.

\section{Presentación}

Los antropólogos solemos tratar a las poblaciones humanas a partir de personas que nos parecen ejemplos representativos de la cultura del grupo social al que pertenecen, ya que es precisamente la cultura - y sus diversos aspectos y problemas - lo que nos interesa investigar y mostrar a propios y extraños, profanos y conocedores. Evitamos en la medida de lo posible el ser confundidos con sociólogos, es decir, dejamos de utilizar la estadística (siquiera básica) que ha dado especificidad - fama incluso- al gremio de dichos colegas por tratarse de una herramienta «innecesaria» para efecto de comprender, mostrar e incluso discutir los temas clásicos de la antropología social, cuyos orígenes hunden sus raíces en el siglo XIX.

Sin embargo, y para el efecto de estudiar especificidades de grupos sociales en un país que como México ha sido el escenario de cambios demográficos de magnitudes insospechadas, en ocasiones verdaderamente incomprensibles, resulta imprescindible e inevitable — necesario me atrevería a decir- el «hincarle el diente» a los datos estadísticos básicos para dar cuenta tanto de la magnitud de los cambios culturales como de sus orígenes y de sus causas.

En esta ocasión, en parte para defender la legitimidad de dicha aseveración pero sobre todo para mostrar la necesidad de volver la mirada a los datos estadísticos — aun cuando no contemos con una formación mínima básica para el 
efecto (me atrevo a aseverar que, como cualquier migrante lo hace, aprenderemos por necesidad casi cualquier cosa)—, en este ensayo trataré resumidamente, y a partir de los cambios demográficos ocurridos desde I950 en 5 de los I I estados costeros mexicanos cuyas playas baña el océano Pacífico y elegidos por la diversidad de situaciones que presentan, los intensos procesos de desarrollo impuestos - aunque no del todo controlados- por el Estado mexicano sobre el territorio y cómo han afectado a las comunidades de pescadores artesanales nativos. El texto que ahora pongo frente a los ojos de su lector es la primicia de un libro que preparo sobre los mismos aspectos, pero no sólo en las costas mexicanas frente al Pacífico — como es el caso que ahora nos ocupa—, sino en el conjunto completo de ellas.

La república mexicana está dividida para su gobierno en 3 I «entidades federativas» mejor conocidas con el nombre de «Estados» y un Distrito Federal conocido también como Ciudad de México. El DF está dividido a su vez en I 6 «delegaciones», mientras los Estados están divididos en «municipios», que suman 2.440. Las delegaciones del DF están gobernadas por un jefe delegacional; los Estados tienen a la cabeza un gobernador y los municipios a un presidente municipal o alcalde, todos ellos elegidos por el voto directo y secreto de los habitantes de la jurisdicción de que se trate. En principio, cada Estado es libre y soberano (no depende del Presidente de la República) y cada municipio también, por lo que en teoría tampoco depende del gobernador del Estado al que pertenece. En cambio la República de Chile está compuesta por I 5 regiones, cada una a cargo de un intendente elegido por el Presidente de la República, y 5 I provincias, cada una a cargo de un gobernador nombrado y removido libremente por el Presidente de la República. Cada provincia está conformada a su vez por comunas ( 342 en total en 2010) dirigidas por un alcalde electo por votación popular.

A nuestro gentil y paciente lector debo decirle además que el propósito de este texto es doble. Por un lado, el de mostrar que los cambios demográficos son un indicador magnífico, sin igual — aunque indirecto ciertamente- de la inversión de capitales en actividades económicas que requieren de un territorio particular en donde manifestarse. Por otro, que los cambios demográficos son sustantivos para formarnos un criterio de análisis de la relación entre territorio y desarrollo; y que, además, el análisis cuantitativo básico es imprescindible - aún para los antropólogos sociales- para intentar responder a las preguntas de naturaleza «teórica» sobre los procesos de desarrollo en las costas de nuestra América. 


\section{Introducción}

Siendo México un país que tiene un poco más de I r.00o kilómetros de litorales ubicados frente a tres rostros marinos completamente diferentes entre sí (el Golfo de México, el Océano Pacífico y el Mar Caribe; véase el mapa dgital de México en la figura I) y habiendo sus habitantes nativos desarrollado en ellos una tradición pesquera y marítima arqueológicamente conocida, sorprende a muchos el hecho de que durante los más de dos siglos de vida independiente, el desarrollo socioeconómico, y en particular demográfico del país, haya ido abriéndose camino casi exclusivamente en tierra adentro. Sin embargo, aproximándonos con mirada inquisitiva y desprejuiciada a ciertos hechos sustantivos en la configuración de la historia de México ya no es sorprendente que el desarrollo del país se verificara fundamentalmente en territorios alejados de sus costas.

El primero de entre esos hechos es que durante los tres siglos de vida colonial las costas de nuestro país estuvieron prácticamente deshabitadas. Sólo en algunos puertos como Veracruz y Campeche (frente al Golfo de México) se mantuvo y creció poco a poco la población costeña. El fenómeno guarda estrecha relación con las epidemias entre los indígenas - que en tierras costeñas resultaron virulentísimas- y con las consecuentes y gravísimas hambrunas, amén del impacto que tuvo sobre una sociedad nativa muy estructurada

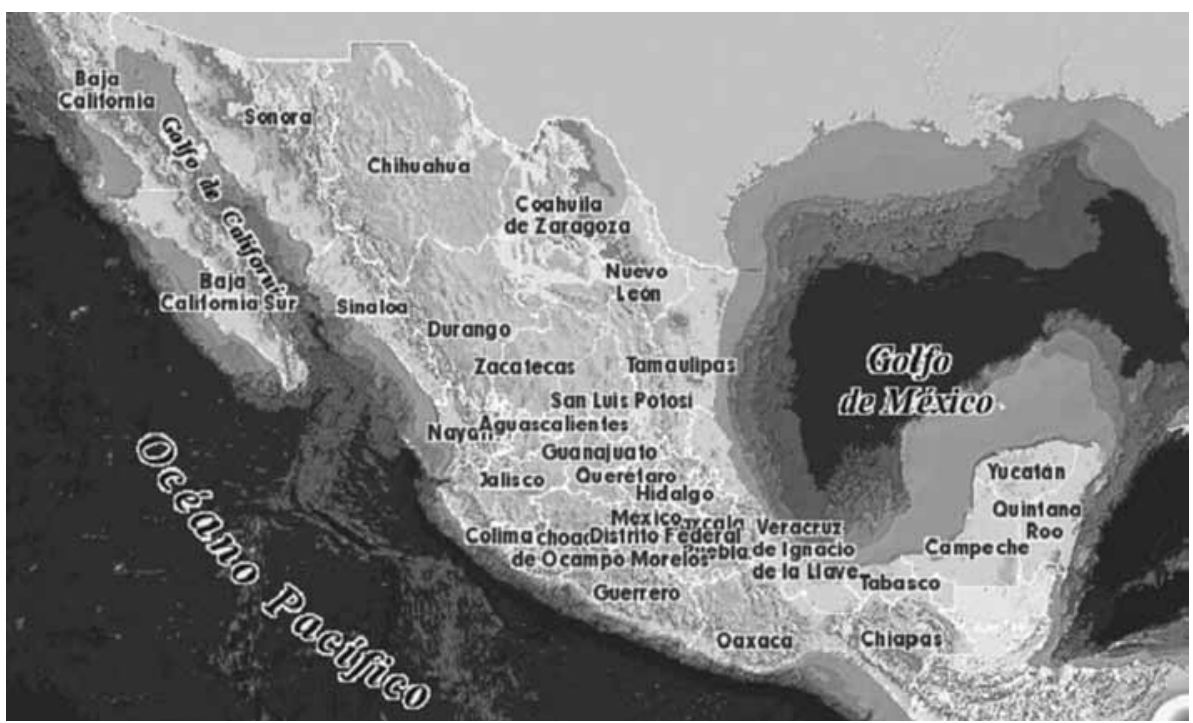

Figura 1. Mapa de México 
el desmembramiento de sus unidades político-administrativas a resultas de la guerra armada misma. Los historiadores calculan que durante el primer siglo de contacto, el siglo XVI, entre el 85 y el $95 \%$ de la población indígena, que se calcula fluctuaba entre 20 y 25 millones de personas, desapareció (véase Cook y Borah, I980; Romano, 2004).

La recuperación demográfica en el centro de la Nueva España, iniciada alrededor de I620-1625, en Chiapas — sureste del virreinato- se retrasó hasta fines del siglo XVIII (Viqueira, I995). Los procesos de recuperación demográfica en Nueva España, incluso en Chiapas, no tuvieron como escenario a sus costas, casi todas ubicadas en la zona intertropical del planeta, en donde fiebres diversas y enfermedades endémicas sólo empezaron a ser controladas muy entrado el siglo xx gracias al uso masivo del DDT, hoy prohibido incluso en México (Comisión para la Cooperación Ambiental, 200I).

La conformación del México independiente durante el siglo XIX fue larga y penosa: enfrentó desavenencias internas — guerra civil— entre «liberales»y «conservadores»; varias invasiones extranjeras (norteamericana y francesa); un largo proceso de confección de constituciones que pudiesen ser la norma de organización de la convivencia interna, así como garantes de la soberanía sobre el territorio frente a potencias extranjeras; una compleja readaptación de las formas coloniales de tenencia de la tierra, mayoritariamente en manos de la Iglesia Católica y de las comunidades indígenas a las que se les fue despojando para dar paso a fines de aquel siglo a una nación «mestiza», arraigada a la tierra por una forma casi esclava de relación de trabajo en las haciendas.

Entonces un segundo y también principalísimo motivo por el cual el desarrollo de México se planificó y concretó tierra adentro es que hasta hace apenas tres o cuatro décadas la nación mexicana la formaban campesinos descendientes de aquéllos que lucharon la primera gran revolución moderna del siglo xx en el planeta: la Revolución mexicana de I9ıo, cuyo leit motiv fue el cambio de la propiedad y del control de la tierra.

Cuando pasadas cuatro décadas del inicio de dicha revolución ésta se había vuelto gobierno pero no les había «hecho justicia», los campesinos iniciaron una migración constante y masiva desde sus lugares de origen, en tierra adentro, hacia la Ciudad de México primero y, más tarde, durante la década I960I970 también hacia Guadalajara, Jalisco, y Monterrey, Nuevo León. Ciudades ambas que desde entonces se consideran a sí mismas la segunda ciudad más grande e importante del país (Garza, 2002).

Sólo durante las últimas cuatro décadas de la historia de México se ha ido 
perfilando una planificación territorial del país que abarca sus zonas costeras. Analizar estos aspectos en los territorios costeros de México, territorios que se han estado transformando de manera acelerada y en ocasiones ambientalmente desastrosa, me ha llevado a crear desde hace una década el concepto «región costera", concepto nominalista que guarda las funciones de una herramienta que permita llevar a cabo el análisis regional en los territorios costeros y efectuar, en su momento, comparaciones posibles de los referentes empíricos del mismo.

Una región costera — que denominé litoral en un primer momento- es aquélla que configuran los hombres al efectuar actividades productivas, extractivas, de captura y/o de recreo y deporte en el espacio costero y en el mar ribereño que lo rodea y que puede extenderse o no hacia mar abierto, debido ya sea a que hacia él se despliega el ejercicio de sus actividades, ya sea porque el mar es un espacio «aprehendido» por su imaginario cultural (Alcalá, 1999).

Utilizamos este concepto para guiar nuestras investigaciones cuando nos interesa colocar en el centro del análisis a los distintos grupos sociales y a las actividades que despliegan en el espacio a lo largo del tiempo — histórico, por supuesto-, actividades que tienen un sentido precisamente porque el trabajo de hombres y mujeres concretos las hacen posibles. Los dos aspectos sustantivos que debemos conocer para intentar efectuar un análisis serio de las regiones costeras son, a mi entender, los contextos básicos de toda sociedad humana: el contexto demográfico y el contexto espacio-temporal (historia, economía, geografía y oceanografía) del referente empírico de nuestro interés.

Empecemos entonces por el principio: veamos ahora cuáles han sido los cambios demográficos en las costas del Pacífico mexicano, sus principales causas y sus principales consecuencias.

\section{Demografía y actividades económicas en los Estados costeros ubicados en el litoral del Pacífico mexicano}

En México y hasta hace apenas una década, la voluntad imperial de los Presidentes de la República tenía efectos concretos en la administración pública y en los territorios nacionales, esto es, en el desarrollo nacional. Pautas y velocidad del crecimiento económico, formas de llevarlo a cabo, maneras de 
convencer, y, lo que es definitivo, montos de inversiones de capital federal, estatal e incluso privado eran objeto de la decisión de cada Presidente y de sus principales asesores (Alcalá, 2003).

Durante el sexenio del Presidente Luis Echeverría (I970-I976), el país experimentó los primeros y acelerados cambios demográficos a nivel nacional producto de la política del Presidente tanto a nivel de la inversión de capital público en las actividades que mencionamos en el anterior apartado, como de aquéllas relacionadas directamente con la población. Los principales cambios fueron los siguientes:

- Un increíble decrecimiento de la tasa de natalidad en tiempo récord, para sorpresa de los demógrafos, quienes no comprendieron la muy positiva respuesta de las mujeres mexicanas a las campañas de control de la natalidad que ofrecían gratuitamente medicamentos y apoyo. Como resultado también de la primera y única campaña dirigida a los hombre llamada «Paternidad responsable».

- El inicio de la migración hacia los lugares de inversión pública en turismo en las costas del Pacífico y el Caribe mexicanos.

Durante todo su sexenio, el Presidente Echeverría estuvo interesado en llevar crecimiento económico y desarrollo a las costas del país. Para lograrlo invirtió en la construcción de infraestructura para la pesca y en la capacitación técnica, administrativa y contable de los pescadores; en la infraestructura turística y de comunicación terrestre y aérea a gran escala; y en la infraestructura para la generación de energía eléctrica y la obtención de hidrocarburos. El resultado de todo ello fue positivo para distintas regiones del país, pero trajo consigo el inicio de un endeudamiento mayúsculo del que recién hace una década empezamos a recuperarnos.

¿Qué sucedió demográficamente hablando en los once Estados que conforman la costa mexicana frente al Pacífico un poco antes de la llegada del Presidente Echeverría al poder y hasta el día de hoy? Sucedió algo inédito en los anales de la historia demográfica del país, algo que además todavía no hemos analizado en profundidad en términos de sus consecuencias medioambientales, socioeconómicas y menos aún políticas, pero que es de suyo fundamental comprender.

Entre los once Estados que se encuentran frente al Pacífico mexicano Baja California, Baja California Sur, Sonora, Sinaloa, Nayarit, Jalisco, Coli- 
ma, Michoacán, Guerrero, Oaxaca y Chiapas- existen en realidad grandes diferencias entre sí, no sólo culturales, económicas y de composición social geográficas y oceanográficas. Sin embargo, y a pesar de ello, tienen en común un comportamiento demográfico que realmente sorprende. Debido a que sería demasiado extenso este artículo si expongo los datos de dichos once Estados, sólo mostraré aquí los datos de cinco de entre ellos elegidos para mostrar la mayor diversidad posible: Baja California, Sinaloa, Jalisco, Michoacán y Chiapas.

De I950 a I973, Baja California se llamó oficialmente Baja California Norte y no tenía la calidad de Estado, sino sólo el de «territorio» debido a su escasísima población, menor a 250.000 personas viviendo replegadas sobre el litoral. Gracias a la pesca obtenían alimentos y productos marinos para el comercio. Si bien el extremo norte del mar de Cortés forma parte de su territorio, es frente al Pacífico que la población humana habita. Esta costa, bañada por la Corriente de California, es incluso hospitalaria por su clima mediterráneo con un régimen de lluvias en otoño e invierno. En aquélla viajan desde la zona interpolar del planeta grandes ballenas que en las dos últimas décadas se han convertido en un atractivo turístico inmejorable gracias a la prohibición de cazarlas - declarada por el gobierno mexicano- y al cuidado que les procuran los pescadores nativos. Cada año llegan para aparearse y crecer a sus ballenatos durante nuestro invierno — diciembre, enero, febrero- para luego regresar con ellos al norte, a sus lugares de alimentación preferidos.

A partir de 1970, por efecto del crecimiento de la actividad pesquera industrial de atún, sardina y anchoveta y, más tarde, gracias al crecimiento del turismo de fin de semana que llega desde Estados Unidos por carretera y de

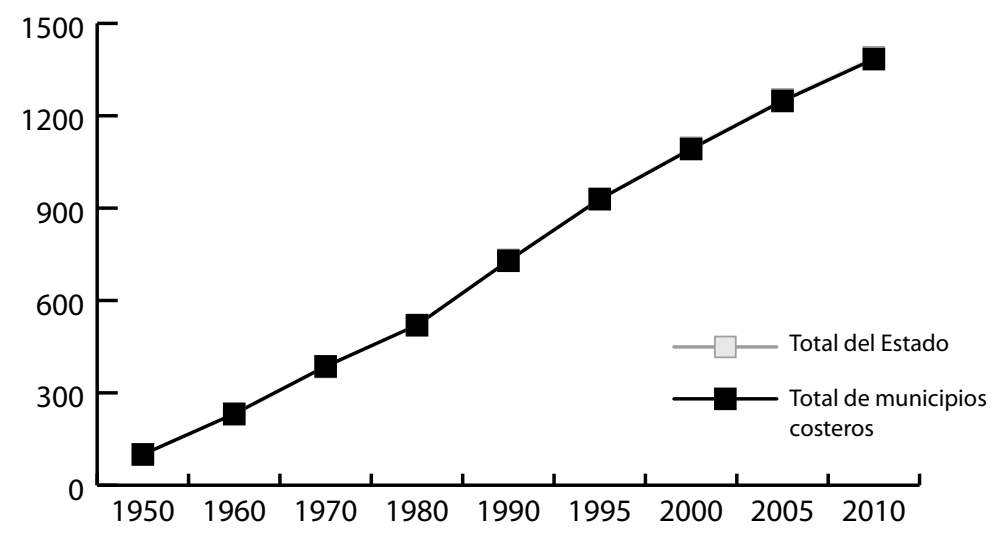

Gráfico 1. Población de Baja California y sus municipios costeros (población en $1950=100$ ) 
Tabla 1. Municipios de baja California y población censada

\begin{tabular}{lccccccccc} 
Municipios & 1950 & 1960 & 1970 & 1980 & 1990 & 1995 & 2000 & 2005 & 2010 \\
$\begin{array}{l}\text { Playas de } \\
\text { Rosarito }\end{array}$ & & & & & & 46.596 & 63.42 & 73.305 & 90.668 \\
\hline Tijuana & 65.354 & 165.690 & 340.583 & 461.257 & 747.381 & 991.592 & 1.210 .820 & 1.510 .687 & 1.559 .683 \\
\hline Ensenada & 31.067 & 64.934 & 115.423 & 175.425 & 259.979 & 315.289 & 370.73 & 413.481 & 466.814 \\
\hline Mexicali & 124.362 & 281.333 & 396.324 & 510.664 & 601.938 & 696.034 & 764.602 & 855.962 & 936.826 \\
\hline
\end{tabular}

\begin{tabular}{lccccccccc}
$\begin{array}{l}\text { Total municipios } \\
\text { costeros }\end{array}$ & 220.793 & 511.957 & 852.33 & 1.147 .346 & 1.609 .298 & 2.051 .506 & 2.411 .572 & 2.755 .440 & 3.056 .001 \\
$\begin{array}{l}\text { Total municipios } \\
\text { no costeros }\end{array}$ & 6.172 & 8.208 & 18.091 & 30.54 & 51.557 & 60.634 & 75.795 & 89.029 & 99.069 \\
\hline $\begin{array}{l}\text { Total del Estado } \\
226.965\end{array}$ & 520.165 & 870.421 & 1.777 .886 & 1.660 .855 & 2.212 .140 & 2.487 .367 & 2.844 .469 & 3.155 .070
\end{tabular}

$\begin{array}{lccccccccc}\begin{array}{l}\text { Total municipios } \\ \text { costeros }\end{array} & 100 & 231 & 386 & 520 & 729 & 929 & 1.092 & 1.248 & 1.384 \\ \begin{array}{l}\text { Total municipios } \\ \text { no costeros }\end{array} & 100 & 133 & 293 & 495 & 835 & 982 & 1.228 & 1.442 & 1.605 \\ \begin{array}{l}\text { Total del Estado } \\ \text { Totan }\end{array} & 10 & 229 & 384 & 519 & 732 & 931 & 1.096 & 1.253 & 1.390 \\ \begin{array}{l}\% \text { Municipios } \\ \text { costeros }\end{array} & 97 \% & 98 \% & 98 \% & 97 \% & 97 \% & 97 \% & 97 \% & 97 \% & 97 \%\end{array}$

Fuentes: INEGI (1950, 1960, 1970, 1980, 1990, 2000, 2010, 1995, 2005).

cruceros, así como a la producción vitivinícola en la única región de México con clima mediterráneo debido a su ubicación por encima del Trópico de Cáncer, la población humana se ha duplicado cada década. La consecuencia más importante de este crecimiento demográfico es la concentración de más del $85 \%$ de aquélla en dos ciudades: Tijuana, la capital, y Ensenada, «La Cenicienta del Pacífico», antigüo centro de desembarque, enlatado y procesado tanto de atún como de sardina y anchoveta. Dicha concentración ha traído por consecuencia el deterioro de los mantos friáticos de ambas ciudades y el inicio de un desordenado crecimiento urbano. El crecimiento e intensificación de las actividades del narcotráfico en el Estado no parece hacer mella a la tendencia demográfica mostrada.

Sinaloa es un Estado que presenta un comportamiento demográfico único en el conjunto de los once Estados costeros ubicados frente al Pacífico mexicano. En la tabla 2 podemos ver que Navolato, municipio creado recién en I990, creció entre 1990 y 2000 a un ritmo semejante al de otros municipios vecinos pero durante la década 2000-20ı0 disminuyó ligeramente su población. La población del viejo y pequeño municipio de Elota, durante la misma década, 


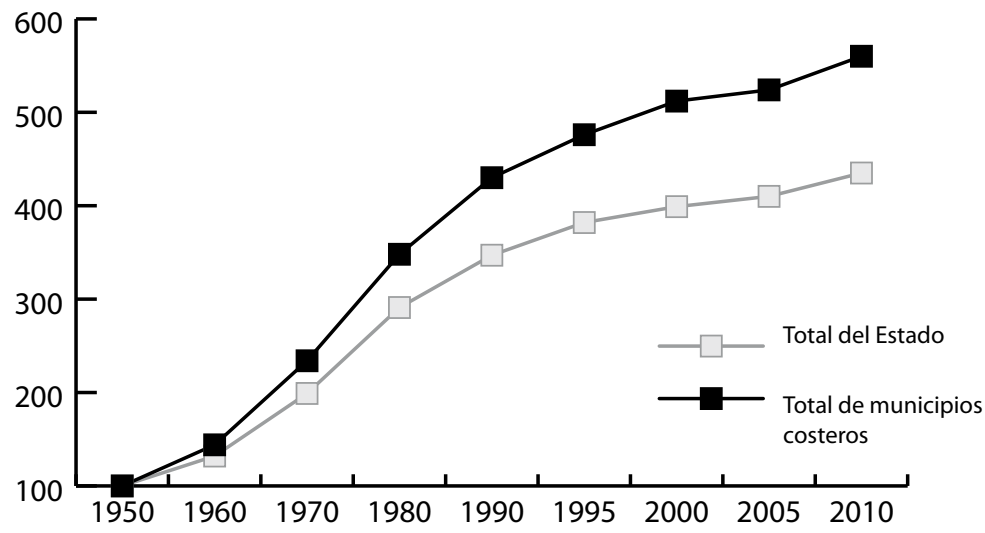

Gráfico 2. Población de baja Sinaloa y sus municipios costeros (población en $1950=100$ )

Tabla 2. Municipios de Sinaloa y población censada

\begin{tabular}{lcccccccccc} 
Municipios & 1950 & 1960 & 1970 & 1980 & 1990 & 1995 & 2000 & 2005 & 2010 \\
\hline Ahome & 60.175 & 89.593 & 164.719 & 254.681 & 303.558 & 340.454 & 359.146 & 388.344 & 416.307 \\
Guassave & 54.631 & 91.024 & 149.663 & 221.139 & 258.13 & 264.225 & 277.402 & 270.260 & 285.919 \\
\hline Agostura & 10.612 & 12.631 & 29.309 & 44.529 & 47.324 & 47.095 & 43.827 & 42.445 & 44.993 \\
\hline Navolato* & & & & & 131.973 & 132.365 & 145.662 & 135.681 & 135.603 \\
\hline Culiscán & 147.106 & 208.982 & 360.412 & 560.011 & 601.123 & 698.262 & 745.537 & 793.73 & 858.631 \\
\hline Elota & 8.765 & 12.22 & 17.572 & 24.766 & 30.599 & 34.49 & 49.471 & 46.462 & 42.968 \\
\hline San Ignacio & 19.482 & 23.212 & 23.332 & 24.825 & 24.235 & 27.101 & 47.934 & 23.355 & 22.527 \\
\hline Mazatlán & 76.866 & 112.619 & 167.616 & 249.988 & 314.345 & 357.619 & 380.509 & 403.888 & 438.415 \\
\hline Rosario & 27.303 & 34.881 & 39.728 & 44.740 & 47.716 & 49.240 & 47.934 & 47.394 & 49.379 \\
\hline Escuinapa & 14.949 & 17.994 & 30.807 & 37.666 & 45.928 & 49.474 & 50.438 & 49.665 & 54.127
\end{tabular}

\begin{tabular}{llllllllll}
$\begin{array}{l}\text { Total municipios } \\
\text { costeros }\end{array}$ & 419.789 & 603.156 & 983.158 & 1.462 .345 & 1.804 .631 & 1.998 .325 & 2.147 .820 & 2.201 .214 & 2.348 .869 \\
$\begin{array}{l}\text { Total municipios } \\
\text { no costeros }\end{array}$ & 215.892 & 235.248 & 283.370 & 387.534 & 399.423 & 427.350 & 389.024 & 407.228 & 418.992 \\
\hline $\begin{array}{l}\text { Total del Estado } \\
635.681\end{array}$ & 838.404 & 1.266 .528 & 1.849 .879 & 2.204 .054 & 2.425 .675 & 2.536 .844 & 2.608 .442 & 2.767 .761
\end{tabular}

\begin{tabular}{lccccccccc}
$\begin{array}{l}\text { Total municipios } \\
\text { costeros }\end{array}$ & 100 & 144 & 234 & 348 & 430 & 476 & 512 & 524 & 560 \\
$\begin{array}{l}\text { Total municipios } \\
\text { no costeros }\end{array}$ & 100 & 109 & 131 & 180 & 185 & 198 & 180 & 189 & 194 \\
\hline $\begin{array}{l}\text { Total del Estado } \\
\text { Totanicipios }\end{array}$ & 100 & 132 & 199 & 291 & 347 & 382 & 399 & 410 & 435 \\
$\begin{array}{l}\text { \% Mun } \\
\text { costeros }\end{array}$ & $66 \%$ & $72 \%$ & $78 \%$ & $79 \%$ & $82 \%$ & $82 \%$ & $85 \%$ & $84 \%$ & $85 \%$
\end{tabular}

Fuente: INEGI (1950, 1960, 1970, 1980, 1990, 2000, 2010, 1995, 2005). 
decreció en poco más de un $8 \%$; la población de San Ignacio decreció en más del 50\% (hoy tiene una población semejante a la que tenía en I950). Rosario ha experimentado un ligero decrecimiento de su población entre I995 y 2000, luego un estancamiento entre 2000 y 2005 para volver a tener en 2010 más o menos el mismo número de pobladores que tenía en I995. Escuinapa tiene un comportamiento más o menos parecido. En todos estos municipios costeros, contrariamente a la tendencia a crecer aceleradamente que se observa en el resto de municipios costeros del país, sus habitantes están huyendo de sus pueblos víctimas de las actividades del narcotráfico organizado, particularmente de la violencia armada que se ha desatado entre distintos «cárteles». Los pescadores artesanales de la zona fueron los primeros en ser perjudicados y en dar aviso a las autoridades pero ninguna les hizo caso. (Durante los años 2000 a 2005 tuve la oportunidad de hacer trabajo de campo por esas latitudes en compañía de otro colega. Las ejecuciones de pescadores en lagunas costeras, esteros y meandros estaban a la orden del día. Las amenazas que recibían de los criminales organizados ordenándoles que dejasen de transitar por ciertas áreas, seguidas de asesinatos feroces perpetrados contra ellos y contra miembros de sus familias disuadieron rápidamente a todos. Las mejores zonas de captura de camarón en aguas protegidas las perdieron cediendo el tránsito en ellas a los narcotraficantes.) Estos pequeños municipios, comparados con Mazatlán, Culiacán (la capital del Estado), Ahome y Guasave que marcan la pauta de la tendencia demográfica en la costa, no son numéricamente significativos. Pero sí son una muestra fehaciente de los estragos que las actividades del narcotráfico están causando en el país y de la pérdida paulatina pero constante de soberanía que sobre el territorio debiese ejercer el propio Estado mexicano.

La agricultura, la ganadería y la pesca son las principales actividades económicas en el Estado. Los municipios costeros son su escenario, por lo que el crecimiento demográfico es acelerado y constante a partir de la década de I970. Las inversiones en los sectores productivos y de servicios provienen en buena medida del gobierno federal.

Las principales actividades productivas en el estado de Jalisco son la industria (productos alimenticios y bebidas, fabricación de productos químicos, de materiales para la construcción, etcétera), la agricultura y la ganadería, ocupando desde 1995 aproximadamente el primer lugar nacional en producción de maíz de grano, maíz forrajero, agave tequilero, garbanzo forrajero, lima, carne de aves, leche de bovino, huevo, ganado porcino y ganado bovino.

Pero destaca también en actividades del sector terciario, particularmente en 


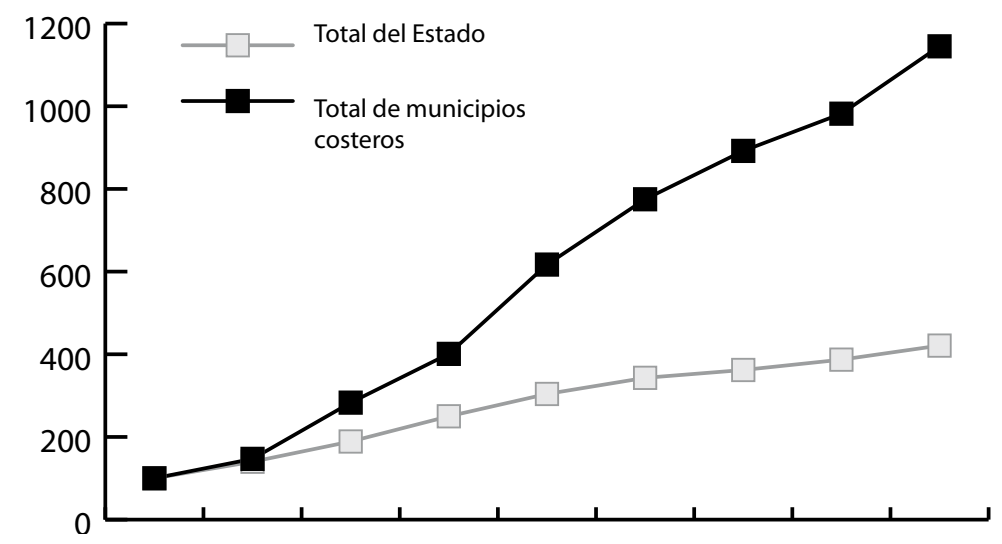

Gráfico 3. Población de Jalisco y sus municipios costeros (población en $1950=100$ )

Tabla 3. Municipios de Jalisco y población censada

\begin{tabular}{|c|c|c|c|c|c|c|c|c|c|}
\hline Municipios & 1950 & 1960 & 1970 & 1980 & 1990 & 1995 & 2000 & 2005 & 2010 \\
\hline Puerto Vallarta & 10.801 & 15.462 & 35.911 & 57.028 & 11.457 & 149.876 & 184.728 & 220.368 & 255.681 \\
\hline $\begin{array}{l}\text { Cabo } \\
\text { Corrientes }\end{array}$ & 4.363 & 5.077 & 5.068 & 6.785 & 8.146 & 8.744 & 9.133 & 9.034 & 10.029 \\
\hline Tomatlám & 5.806 & 9.160 & 16.724 & 23.586 & 30.750 & 33.872 & 34.329 & 31.798 & 35.050 \\
\hline La Huerta & 4.980 & 9.424 & 15.950 & 19.282 & 20.678 & 22.432 & 22.827 & 20.161 & 23.428 \\
\hline Cihuathán & 5.774 & 7.515 & 16.217 & 20.452 & 24.855 & 30.955 & 32.019 & 30.241 & 39.020 \\
\hline $\begin{array}{l}\text { Total municipios } \\
\text { costeros }\end{array}$ & 31.724 & 46.638 & 89.870 & 127.134 & 195.886 & 245.879 & 283.036 & 311.602 & 363.208 \\
\hline $\begin{array}{l}\text { Total municipios } \\
\text { no costeros }\end{array}$ & 1.715 .053 & 2.396 .623 & 3.208 .716 & 4.244 .864 & 5.106 .803 & 5.745 .297 & 6.038 .966 & 6.440 .511 & 6.987 .474 \\
\hline Total del Estado & 1.746 .777 & 2.443 .261 & 3.298 .586 & 4.371 .998 & 5.302 .689 & 5.991 .176 & 6.322 .002 & 6.752 .113 & 7.350 .682 \\
\hline $\begin{array}{l}\text { Total municipios } \\
\text { costeros }\end{array}$ & 100 & 147 & 283 & 401 & 617 & 775 & 892 & 982 & 1,145 \\
\hline $\begin{array}{l}\text { Total municipios } \\
\text { no costeros }\end{array}$ & 100 & 140 & 187 & 248 & 298 & 335 & 352 & 376 & 407 \\
\hline Total del Estado & 100 & 140 & 189 & 250 & 304 & 343 & 362 & 387 & 421 \\
\hline $\begin{array}{l}\% \text { Municipios } \\
\text { costeros }\end{array}$ & $2 \%$ & $3 \%$ & $3 \%$ & $4 \%$ & $4 \%$ & $4 \%$ & $4 \%$ & $5 \%$ & $5 \%$ \\
\hline
\end{tabular}


el turismo, no sólo de playa y de cruceros sino en general. Su principal atractivo en la costa es Puerto Vallarta y sus alrededores montañosos y de exuberante vegetación ubicados tanto en territorio de Jalisco como en territorio nayarita (Alcalá, en prensa).

Puerto Vallarta es producto del impulso federal por crear un emporio turístico en una zona que había llamado la atención del mundo entero gracias a la filmación en sus inmediaciones de la conocida película La noche de la iguana dirigida por John Ford en I964. En I 970 el Presidente Gustavo Díaz Ordaz se comprometió a construir el polo de desarrollo turístico que es hoy e inició los trabajos correspondientes invitando al entonces Presidente de Estados Unidos a encontrarse con él en Puerto Vallarta y visitar juntos el «rústico pueblecito». Y es también a partir de ese momento que, como se observa en la tabla 3 , el crecimiento demográfico del municipio se disparó.

Si la inversión fluye a la costa creando trabajo en donde no había prácticamente nada, la migración también. El resto de municipios costeros de Jalisco, cuyas actividades han sido tradicionalmente la agricultura y la ganadería extensiva no presentan cambios demográficos significativos desde 1950 a la fecha.

La capital del Estado es la ciudad de Guadalajara, la segunda en importancia en el país, pero su crecimiento demográfico no es proporcionalmente mayor que el de Puerto Vallarta. Los problemas a que se enfrenta hoy en día dicho crecimiento sin tregua son los de las ciudades medias mexicanas en general: falta de agua para consumo humano (a pesar de que las lluvias ahí inundan periódicamente la ciudad), aumento incontrolable de desechos cuyo reciclaje no se vislumbra siquiera, serios problemas de tránsito de vehículos de motor, y el aumento significativo de problemas de drogadicción entre los jóvenes.

En Michoacán el acelerado crecimiento de la población en la cabecera municipal del municipio costero, Lázaro Cárdenas, es un ejemplo paradigmático sin más de las consecuencias que tenían las decisiones que antaño podían llegar a tomar y tomaban de hecho los Presidentes de México. Si bien en la costa michoacana no habita ni siquiera el $5 \%$ de la población total del Estado excepción total a la tendencia promedio que hemos venido mostrando-, es en ella en donde se manifiesta con mayor potencia el crecimiento demográfico derivado de la inversión de capital federal en una empresa, que en este caso poco tiene que ver con la pesca (Alcalá, I986) y/o el turismo y si mucho con las decisiones de los gobiernos federales para aprovechar las características orográficas de la zona y sus condiciones litorales. 


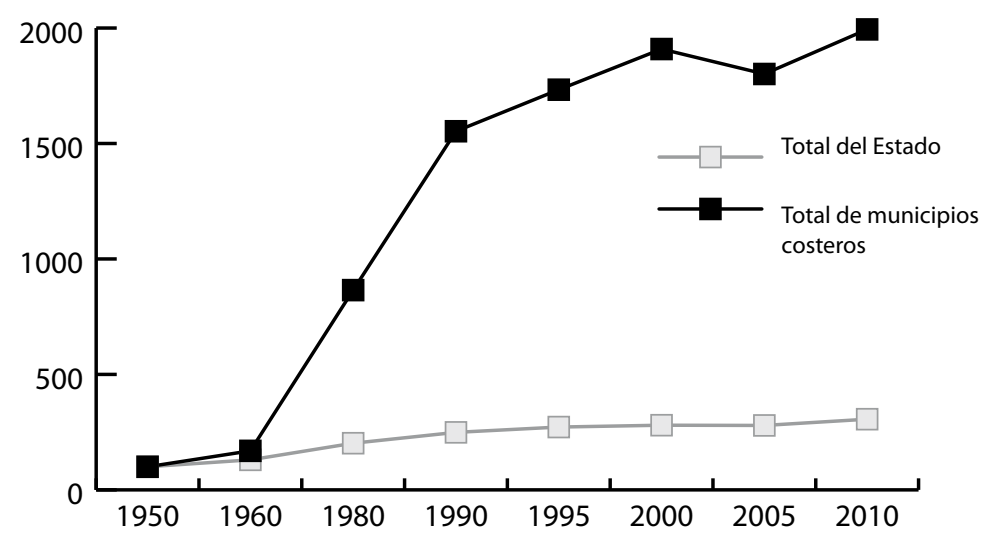

Gráfico 4. Población de Michoacán y sus municipios costeros (población en 1950 = 100)

Tabla 4. Municipios de Michoacán y población censada

\begin{tabular}{|c|c|c|c|c|c|c|c|c|}
\hline Municipios & 1950 & 1960 & 1980 & 1990 & 1995 & 2000 & 2005 & 2010 \\
\hline Coahuayana & 4.029 & 6.661 & 13.378 & 13.369 & 13.974 & 13.974 & 11.632 & 14.136 \\
\hline Aquila & 6.826 & 11.693 & 19.726 & 20.275 & 19.411 & 22.152 & 20.898 & 23.536 \\
\hline \multicolumn{3}{|l|}{$\begin{array}{l}\text { Lázaro } \\
\text { Cárdenas }\end{array}$} & 62.355 & 134.969 & 155.366 & 171.100 & 162.997 & 178.817 \\
\hline $\begin{array}{l}\text { Total municipios } \\
\text { costeros }\end{array}$ & 10.855 & 18.354 & 93.934 & 168.622 & 188.146 & 207.226 & 195.527 & 216.489 \\
\hline $\begin{array}{l}\text { Total municipios } \\
\text { no costeros }\end{array}$ & 1.411 .862 & 1.833 .522 & 2.774 .890 & 3.379 .577 & 3.682 .458 & 3.778 .441 & 3.770 .546 & 4.134 .548 \\
\hline Total del Estado & 1.422 .717 & 1.851 .876 & 2.868 .824 & 3.548 .199 & 3.870 .604 & 3.985 .667 & 3.966 .073 & 4.351 .037 \\
\hline $\begin{array}{l}\text { Total municipios } \\
\text { costeros }\end{array}$ & 100 & 169 & 865 & 1.553 & 1.733 & 1.909 & 1.801 & 1.994 \\
\hline $\begin{array}{l}\text { Total municipios } \\
\text { no costeros }\end{array}$ & 100 & 130 & 197 & 239 & 261 & 268 & 267 & 293 \\
\hline Total del Estado & 100 & 130 & 202 & 249 & 272 & 280 & 279 & 306 \\
\hline $\begin{array}{l}\% \text { Municipios } \\
\text { costeros }\end{array}$ & $1 \%$ & $1 \%$ & $3 \%$ & $5 \%$ & $5 \%$ & $5 \%$ & $5 \%$ & $5 \%$ \\
\hline Fuentes: INEGI (195 & $50,1960,1970$ & 1980,1990 & $00,2010,1$ & $5,2005)$ & & & & \\
\hline
\end{tabular}

Ciudad y puerto, Lázaro Cárdenas es la consecución del sueño que en 1938 tenía el Tata Lázaro - como se le conocía en Michoacán, la tierra que lo vio nacer en mayo de s 895- para lograr la modernización — sinónimo entonces de industrialización - de su patria y, de paso, hacerlo gracias a las materias primas y condiciones costeras de su matria (concepto acuñado por el historiador mexicano don Luis González y González para denominar el lugar de 
donde cada persona es oriunda, lo que en México llamamos «mi tierra» y a la que tienden sus querencias identitarias; en este caso utilizo el concepto con demasiada amplitud pues lo hago en referencia al estado en el que nació el Tata Lázaro). Ese sueño no pudo volverlo realidad él mismo durante su periodo presidencial (I934-I938). Lo logró en I974, cuarenta años más tarde, a través de convencer al Presidente Echeverría de las bondades de su proyecto.

¿Cuál era ese proyecto tan importante para México y para Tata Lázaro? ¿En mil novecientos setenta y tantos tenía todavía sentido el proyecto? De ser así: ¿quién y cómo lograría diseñar — de entrada— la hazaña de convertir un lugar en donde efectivamente había sólo minas de hierro, la desembocadura del río más caudaloso del país y un ejido a su vera habitado por menos de 300 personas en el complejo siderúrgico industrial y portuario más grande e importante del país?

Además de tener la genial idea del proyecto de siderúrgica rondándole la cabeza incesantemente durante cuarenta años, el general Cárdenas ofrecía al Presidente Echeverría proveerle también con la mano de obra técnicamente calificada para dirigir y acompañar las imprescindibles obras previas a la construcción de la propia siderúrgica, pues sin ellas sería imposible echarla a andar: las presas para dominar las corrientes del Balsas en la parte baja de su cuenca y las obras de construcción de una termoeléctrica que produjese la electricidad que la siderúrgica y sus trabajadores pudiesen demandar para echarla a andar, para habitar al lado de ella en su calidad de obreros especializados de primer a último nivel y para continuar haciéndola funcionar durante décadas. El ingeniero Cuauhtémoc Cárdenas, hijo del general, sería el encargado responsable de esa primera tarea.

Los créditos millonarios para efectuar la magna obra fueron solicitados, negociados y otorgados por diversas instituciones bancarias internacionales y entre 1975 y 1995 la primera, segunda y tercera etapas de construcción de la siderúrgica, nombrada por el Presidente Echeverría Siderúrgica Lázaro Cárdenas-Las Truchas, habían sido concluidas «satisfactoriamente».

Al mismo tiempo había sido construido el puerto por donde se recibía y se recibe el carbón requerido en la siderúrgica y por donde se embarcan varilla, alambrón, y demás productos de acero para la construcción sin menoscabo de un intenso comercio de todo tipo: granos a granel, partes de automóviles, petróleo, chatarra, contenedores, etcétera (Alcalá, 2003). Y simultáneamente también se había construido - también por etapas- una ciudad entera planificada como tal que se empezó a desbordar rápidamente. El crecimiento ur- 
bano que se planeo ordenado y rítmico, es un singular problema que crece y crece año con año; la contaminación generada por la siderúrgica (que ha pasado a ser empresa privada, primero de prestanombres mexicanos: Siderúrgica Villacero y, actualmente, de Mital, la empresa privada india más importante del ramo), así como por empresas derivadas, en aire, tierra y agua es visible y peligrosa para la vida humana; la destrucción masiva del entorno no tiene igual en la vertiente del Pacífico.

La migración hacia Ciudad Lázaro Cárdenas duplicaba la población cada década: si en 1970 no existía la ciudad, en I980 contaba con más de 62.000 habitantes y en I 990 con casi I 35.000 . Durante la década siguiente el crecimiento demográfico disminuyó ostensiblemente e incluso en el conteo del año 2005 disminuyó la población en números absolutos para recuperarse levemente en el censo de 2010. Los otros dos municipios costeros poco habitados, muy abandonados por el gobierno federal, sobreviven apenas y mantienen un crecimiento por debajo del crecimiento promedio nacional.

Es tal el peso de la siderúrgica sobre la vida local y regional de los costeños michoacanos que ni siquiera toman en cuenta ya la constante queja de los ahora escasos pescadores locales respecto a la contaminación acuática de río y mar ribereños.

Así que la actividad pesquera es una actividad cada día menos importante y el turismo como tal no existe, a menos que consideremos turista a empleados técnicos, ingenieros, de cuello blanco que diariamente desfilan por las industrias locales yendo y viniendo entre la Ciudad de México, Ciudad Lázaro Cárdenas y diversos otros lugares del planeta.

Como vemos en la gráfica 5 en el caso de los municipios de la costa de Chiapas a partir de la década de I960 y hasta I990, durante 30 años, el crecimiento demográfico era ligeramente superior que en el conjunto del resto de municipios del Estado. Un polo de desarrollo se estaba construyendo en la frontera litoral con Guatemala a partir de la década de I980: la industria procesadora de atún llamada Pescado de Chiapas, S. A. de C. V. y con ella la infraestructura de comunicaciones necesaria que hiciera posible el milagro de transformar un lugar olvidado de la revolución industrial — sin puerto de altura, sin depósitos de combustible ni para los barcos ni para los camiones de carga y sin captura de atún en su costa- en el instrumento de industrialización más caro y exótico de la frontera sur de México (Alcalá, I999). Pero a partir de 1990 ese crecimiento demográfico en la costa chiapaneca se viene abajo con respecto al del Estado en su conjunto. A partir de aquélla década la costa de 


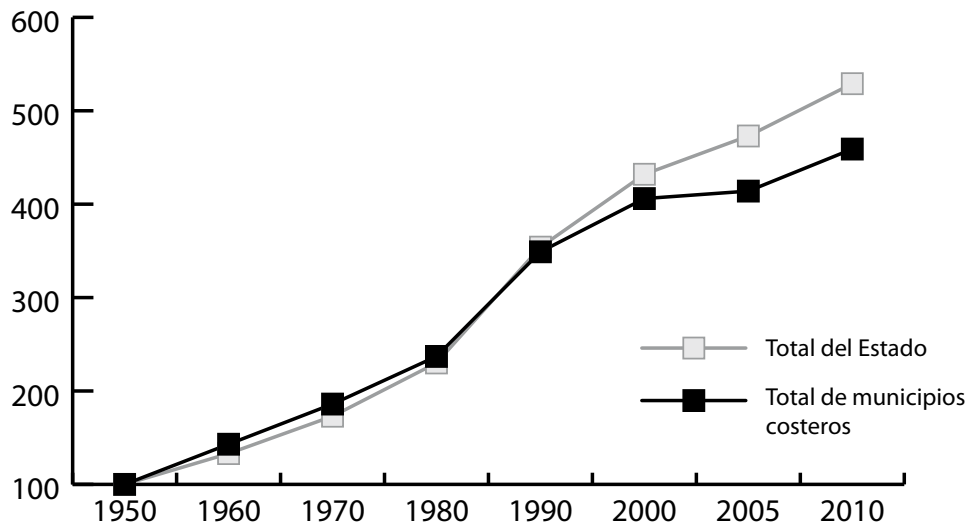

Gráfico 5. Población de Chiapas y sus municipios costeros (población en $1950=100$ )

Tabla 5. Municipios de Chiapas y población censada

\begin{tabular}{|c|c|c|c|c|c|c|c|c|}
\hline Municipios & 1950 & 1960 & 1970 & 1980 & 1990 & 2000 & 2005 & 2010 \\
\hline Acapetahua & 9.849 & 10.156 & 13.300 & 18.277 & 23.871 & 25.154 & 24.165 & 27.58 \\
\hline Arriaga & 14.619 & 19.408 & 24.297 & 31.514 & 36.224 & 37.989 & 38.572 & 40.042 \\
\hline Mapastepec & 7.259 & 11.790 & 17.690 & 23.340 & 34.882 & 39.055 & 37.945 & 43.913 \\
\hline Mazatán & 5.655 & 9.700 & 13.798 & 17.363 & 21.464 & 24.079 & 24.017 & 26.573 \\
\hline Pijijiapan & 10.629 & 15.866 & 21.982 & 28.896 & 43.248 & 46.949 & 46.439 & 50.079 \\
\hline Suchiate & 5.927 & 9.159 & 11.58 & 14.743 & 25.739 & 30.251 & 32.976 & 35.056 \\
\hline Tapachula & 59.760 & 85.064 & 108.056 & 144.057 & 222.405 & 271.674 & 282.420 & 320.451 \\
\hline Tonalá & 22.220 & 31.962 & 40.694 & 44.673 & 67.491 & 78.438 & 78.516 & 84.594 \\
\hline Villa Comaltitán & 7.094 & 10.798 & 14.092 & 16.578 & 24.182 & 26.706 & 26.414 & 27.899 \\
\hline $\begin{array}{l}\text { Total municipios } \\
\text { costeros }\end{array}$ & 143.012 & 203.903 & 265 & 339.441 & 499.506 & 580.295 & 591.464 & 656.187 \\
\hline $\begin{array}{l}\text { Total municipios } \\
\text { no costeros }\end{array}$ & 764.014 & 1.006 .967 & 1.303 .564 & 1.745 .276 & 2.710 .990 & 3.340 .597 & 3.701 .995 & 4.140 .393 \\
\hline Total del Estado & 907.026 & 1.210 .870 & 1.569 .053 & 2.084 .717 & 3.210 .496 & 3.920 .892 & 4.293 .459 & 4.796 .580 \\
\hline $\begin{array}{l}\text { Total municipios } \\
\text { costeros }\end{array}$ & 100 & 143 & 186 & 237 & 349 & 406 & 414 & 459 \\
\hline $\begin{array}{l}\text { Total municipios } \\
\text { no costeros }\end{array}$ & 100 & 132 & 171 & 228 & 355 & 437 & 485 & 542 \\
\hline Total del Estado & 100 & 133 & 173 & 230 & 354 & 432 & 473 & 529 \\
\hline $\begin{array}{l}\% \text { Municipios } \\
\text { costeros }\end{array}$ & $15.8 \%$ & $16.8 \%$ & $16.9 \%$ & $16.3 \%$ & $15.6 \%$ & $14.8 \%$ & $13.8 \%$ & $13.7 \%$ \\
\hline \multicolumn{9}{|c|}{ Fuentes: INEGI (1950, 1960, 1970, 1980, 1990, 2000, 2010, 1995, 2005). } \\
\hline
\end{tabular}


Chiapas se vuelve atípica en su comportamiento demográfico con respecto al resto de las costas del Pacífico mexicano: ¿qué sucedió entonces?

Desde principios de la década de 1990 y con mayor fuerza desde mediados de ésta y a consecuencia de la preocupación que despertó en las autoridades federales y estatales el levantamiento neozapatista iniciado en 1994 (Viqueira y Humberto, I995), las inversiones de capital destinadas a proyectos productivos fueron distribuidas entre los habitantes de los pueblos y comunidades ubicados en los Altos de Chiapas y en la Selva Lacandona. Pero quizá más determinante aún para el desarrollo productivo de los habitantes de la costa chiapaneca fue el hecho de que durante la década de I990 varios huracanes azotaron la zona (Alcalá, I996, 2000) y sus consecuencias fueron fatales para el recién iniciado desarrollo económico de un corredor costero que desde la década de I980 ha sido lugar de paso de migrantes centroamericanos huyendo de la guerra y/o de la miseria imperante en sus respectivos países (Alcalá, I994).

Reconstruir la infraestructura pública —vías de comunicación, escuelas, centros de salud, etcétera- y privada —casas habitación, pequeños negocios, talleres mecánicos, de reparación de electrodomésticos, etcétera- y recuperar la inversión en la ganadería extensiva y en la agroindustria, está siendo un proceso lento que apenas a fines de 2005 empezó a rendir frutos. Primero con la transformación del puerto pesquero-industrial de Puerto Madero —en completo abandono como tal - en puerto de altura para cruceros turísticos rebautizado como Puerto Chiapas por el gobernador entonces en turno (Pablo Salazar Mendiguchía, hoy acusado de malversación de fondos públicos y encarcelado por quien fuese su delfín, el actual gobernador Juan Sabines); luego con la inversión en la reconstrucción completa de la carretera costera; y, finalmente, con el apoyo financiero y comercial a la agricultura ejidal.

Podemos decir que el estancamiento del crecimiento demográfico es algo coyuntural y cíclico en la historia de esta costa ligada en gran medida a los vaivenes del crecimiento económico de nuestra vecina Guatemala.

\section{A manera de conclusiones}

Deseo destacar tres aspectos a manera de reflexiones para cerrar este ensayo.

Un primer aspecto es que existen marcadas tendencias al crecimiento demográfico de los municipios costeros ubicados en el litoral del Pacífico y que dichas tendencias van de la mano con la inversión de capital federal en el desa- 
rrollo de actividades económicas específicas, con pautas evolutivas propias, diferentes unas de otras. Asimismo, es evidente que desde la década de I960, por lo menos, las directrices de las políticas federales están en concordancia con las directrices de los organismos internacionales que condicionan préstamos, servicios administrativos y asesorías técnicas de países como México o Chile a que estos cumplan ciertas condiciones para obtener los citados beneficios.

Simultáneamente llama la atención que los grupos con poder económico en los Estados suelen hacerle eco a las decisiones que el Presidente en turno toma para propiciar el desarrollo -o mejor dicho el crecimiento económico- y nunca enfrentarlas o estar en desacuerdo: suelen en definitiva no oponer resistencia y aprovechan las coyuntura propicia a la llegada de las inversiones federales y/o extranjeras.

Este hecho que parece repetirse en cada uno de los cinco Estados analizados considero que no podemos interpretarlo como una prueba indirecta de debilidad y/o de desinterés de los grupos poderosos locales en el desarrollo de sus costas, sino más bien de cierta imposibilidad financiera para enfrentar obras de largo aliento que son, como hemos visto, las que efectivamente cambian su condición de espacio casi vacío y sin actividades económicas relevantes e incorporan al país territorios olvidados hasta hace unas cuántas décadas. Sólo el Estado nacional puede lograr esta incorporación de hecho ejerciendo su soberanía sobre el territorio y no sólo declarando que es el responsable de ella.

Un segundo aspecto que resulta sumamente inquietante es que las actividades turísticas y portuarias son actividades que si bien alteran el paisaje, esa alteración no es percibida negativamente por los costeños, con excepción de los pescadores quienes son los primeros en quejarse de la impronta que en el paisaje litoral y costero dejan las grandes construcciones para el turismo y los mismos puertos.

Además, en el reparto de beneficiarios del desarrollo costero los pescadores resultan ser los eternos olvidados: a quienes se les suele prometer un lugar en el puerto en construcción y cuando terminan las obras básicas no están contemplados ni embarcaderos ni bodegas ni palapas para que laboren ahí.

Esto manifiesta una forma de discriminación sobre un grupo social y productivo que no termina de desaparecer aunque para algunos tenga ya sus días contados.

El crecimiento demográfico de los municipios costeros viene también a complicar la situación de los pescadores en tanto la atención federal se concentra en los migrantes más que en los descamisados nativos. Tal es el caso del que 
se quejan los pescadores de Mazatlán, Puerto Vallarta, Manzanillo, Ciudad Lázaro Cárdenas, Puerto Chiapas por mencionar sólo a pescadores que así me lo han expresado en entrevistas varias a lo largo de más de 20 años.

¿Cómo podremos lograr un desarrollo equilibrado de las actividades económicas en las costas sin caer en los mismos errores que hasta hoy se han cometido?

Un tercer y último aspecto que deseo plantear es que los nuevos habitantes de las costas mexicanas suelen ser, en su inmensa mayoría, personas llegadas de tierra adentro en busca de un trabajo que les permita alcanzar mejores condiciones de vida. Para estos «costeños» de nuevo cuño la vida en esas latitudes es completamente distinta a la que llevaban en sus lugares de habitación anterior, hayan sido éstos el altiplano o la mesa central, los desiertos norteños, los calcáreos terrenos del interior de la península de Yucatán o las intrincadas laderas de nuestras montañas: nuevos el ritmo y la manera de trabajar, distintas las costumbres alimenticias y de vestimenta locales, desconocidos los fenómenos climáticos y sus consecuencias en la vida cotidiana, extraños los modismos idiomáticos, exótico —en fin- el aprecio de los nativos costeños por su paisaje y su flora y fauna locales.

Para los recién llegados, los «recursos» del lugar son su trabajo y sus relaciones sociales con otros recién llegados con quienes pueden y suelen llegar a compartir techo y comida; para los nativos, sus «recursos» son la flora, la fauna que para el efecto conocen bien, incluso las oficinas del Estado federal y estatal que les pueden facilitar servicios, préstamos, ayudas económicas o simplemente que escuchen sus quejas.

Las diferencias en la percepción del espacio, del paisaje, y en el uso y control del mismo que tienen nativos y fuereños requieren ser conocidas y comprendidas en aras de la mejor convivencia entre las personas.

Quizá los antropólogos sociales, utilizando con maestría la tradicional técnica de la observación participante puedan ayudar a desentrañar dichas diferencias y a hacerlas comprensibles a unos y otros.

\section{Referencias}

Alcalá, G. (1986). Los pescadores de la costa de Michoacán y de las lagunas costeras de Colima y Tabasco. . . ${ }^{a}$ edición. México DF: Centro de Investigaciones y Estudios Superiores en Antropología Social. 
-. (1994). Migrantes, pescadores y mujeres en Puerto Madero. Mesoamérica 25, South Woodstock, Vermont.

-. (1996). Una aproximación al desastre: la modernización impuesta a los pescadores artesanales de El Soconusco. CESMECA de la UNICACH.

-. (I999). Con el agua hasta los aparejos. Pescadores y pesquerías en El Soconusco, Chiapas. CIESAS-CESMECA de la UNICACH-CIAD.

-. (2000). Solidaridad en la desgracia: los pescadores de El Soconusco luego del paso de Mitch por su región. CESMECa de la UnICACH.

-. (2003). Políticas pesqueras en México (1946-2000). Contradicciones y aciertos en la planificación de la pesca nacional. COLMEX-CICESE-COLMICH, vol. 2.

-. (En prensa). Legados del desarrollo: haberes y quehaceres en Bahía de Banderas. IPN, CIIEMAD del IPN, vol. 6.

Comisión para la CoOperación Ambiental. (200I). Historia del DDT en América del Norte a 1997. Comisión para la Cooperación Ambienta.

Cook, S. F., y Borah, W. W. (I980). Ensayos sobre historia de la población. México y California. Tomos I, II, III. Col. América Nuestra. México.

GARZA, G. (2002). Evolución de las ciudades mexicanas en el siglo Xx. N I9, pp. 7-I 7 .

Inegi. (I950). Séptimo Censo General de Población y Vivienda. Disponible en $<$ www.inegi.org.mx>.

-. (1960). Octavo Censo General de Población y Vivienda. Disponible en $<$ www.inegi.org.mx>.

-. (r970). Décimo Censo General de Población y Vivienda. Disponible en <www.inegi.org.mx>.

-. (I980). Décimo primer Censo General de Población y Vivienda. Disponible en $<$ www.inegi.org.mx>.

-. (I990). Décimo segundo Censo General de Población y Vivienda. Disponible en <www.inegi.org.mx>.

-. (I995). Conteo de Población y Vivienda. Disponible en <www.inegi.org. $\mathrm{mx}>$.

-. (2000). Décimo tercer Censo General de Población y Vivienda. Disponible en <www.inegi.org.mx>.

-. (2005). Segundo Conteo de Población y Vivienda. Disponible en <www. inegi.org. $\mathrm{mx}>$.

-. (20I0). Décimo cuarto Censo General de Población y Vivienda. Disponible en $<$ www.inegi.org.mx $>$. 
Romano, R. (2004). Mecanismo y elementos del sistema económico colonial americano. México: Fondo de Cultura Económica y El Colegio de México. Viqueira, J. P. (I995). Chiapas y sus regiones. En Chiapas. Los rumbos de otra historia (pp. I9-40). México DF: UNAM, CIESAM, CEMC, U. de G.

Viqueira, J. P., y Humberto, M. (I995). Chiapas. Los rumbos de otra historia. UNAM, CIESAM, CEMC, U. de G.

\section{Sobre la autora}

Graciela Alcalá es antropóloga del Centro Interdisciplinario de Investigaciones y Estudios sobre Medio Ambiente y Desarrollo del Instituto Politécnico Nacional, México. Su email es <gra2008@me.com>. 
